\title{
Occurrence and spatial pattern of water repellency in a beech forest subsoil
}

\author{
Jörg Bachmann $^{1 *}$, Jiem Krueger ${ }^{1}$, Marc-O. Goebel ${ }^{1}$, Stefanie Heinze ${ }^{2}$ \\ ${ }^{1}$ Leibniz Universität Hannover, Institute of Soil Science, Herrenhäuser Str. 2, 30419 Hannover, Germany. \\ ${ }^{2}$ Geographisches Institut, Ruhr-Universität Bochum, Universitätsstraße 150, 44780 Bochum, Germany. \\ ${ }^{*}$ Corresponding author. E-mail: bachmann@ifbk.uni-hannover.de
}

\begin{abstract}
Most recent studies on soil water repellency (WR) were limited to the humous topsoil or to shallow subsoil layers slightly below the main root zone to approximately $0.5 \mathrm{~m}$ depth. Hence, the main objective of the present study was to investigate the wettability pattern of a forest soil including the deeper subsoil. The selected site was a 100 years old beech forest on a well-drained sandy Cambisol in northern Germany which showed moderate to partly extended acidification. Results obtained from three sampling transects $(3 \mathrm{~m}$ length, $2 \mathrm{~m}$ depth; sampling grid $8 \times 8$ samples per transect; minimum distance of sampling locations to nearest tree about $0.5 \mathrm{~m}$ ) show that contact angles (CA) were always in the subcritical WR range $\left(0^{\circ}<\mathrm{CA}<90^{\circ}\right)$. Significant impact of the tree distance on WR was not observed for any of the transects. A prominent feature of two transects was the minimum WR level $\left(\mathrm{CA}<10^{\circ}\right)$ for samples with soil organic carbon (SOC) contents around $0.25-0.4 \%$. For the topsoils it was observed that CA increased with SOC content from that minimum to a maximum $\mathrm{CA}$ of $60-75^{\circ}$ for transects 1 and 2 with mean $\mathrm{pH}$ values $<3.5$. For transect 3 with slightly higher average $\mathrm{pH}$ close to 4.0 , average CA of samples were always $<10^{\circ}$ and showed no trend to increase with increasing SOC content or other soil parameters like $\mathrm{N}$ content or $\mathrm{C} / \mathrm{N}$ ratio. Subsoil samples, however, behave differently with respect to SOC: for these samples, generally low in SOC, the CA increase with decreasing SOC occurred at all transects for approximately $50 \%$ of the samples but did not show any clear tendencies with respect to further parameters like texture, $\mathrm{pH}$ or $\mathrm{N}$ content. We conclude that the SOC content is the most prominent parameter determining wettability, either positively correlated with WR for topsoils or negatively correlated for subsoil samples very low in SOC. We finally conclude for moderately acid beech forest stands that emerging WR starts in the A horizon after reaching a $\mathrm{pH}$ lower than 3.5, whereas subsoil WR might appear already at higher $\mathrm{pH}$ values. Even SOC contents of $\sim 0.01-0.02 \%$ turned out to be very effective in increasing the CA up to $70^{\circ}$, which points out clearly the importance of small amounts of soil organic matter in affecting subsoil wettability. With respect to site hydrology we conclude that ongoing acidification as well as predicted higher frequencies of extended droughts due to climate change will promote the occurrence of WR with corresponding implications for site and catchment hydrology.
\end{abstract}

Keywords: Beech forest; Soil organic carbon; Subsoil; Water repellency.

\section{INTRODUCTION}

Soil organic matter (SOM) affects many physical, chemical or biological soil properties. Increasing SOM content of mineral soils increase the storage capacity for water and nutrients and improve soil structure and aggregate stability. However, research of the last decades revealed also some negative effects associated with the amount and composition of SOM like soil water repellency (WR), which may lead to adverse effects with respect to soil hydraulic functions. Bachmann et al. (2008) showed that the availability and distribution of water in the soil matrix depends on soil particle wettability. WR occurs in soils of different texture, land use and under a variety of climatic conditions (DeBano, 1981; Doerr et al., 2000; Woche et al., 2005). Mineral surfaces are generally well wettable by water when they are free of any adsorbed organic substances. In contrast to pure mineral surfaces, soil minerals never expose clean surfaces since soil solution carries molecules or colloids of dissolved organic compounds which are easily adsorbed onto mineral surfaces due to the sorption sites and the permanent contact with soil solution. Depending on the type of organic compound, the wetting properties of mineral surfaces may change drastically (Horne and McIntosh, 2003) even after adsorption of only a few molecular layers of organic compounds (Šolc et al., 2015; Zisman, 1964). Formerly wettable mineral or glass surfaces may be rendered strongly water repellent by either specific or non-specific adsorption of hydrophobic substances (Ellerbrock et al., 2005; Lamparter et al., 2014; Šolc et al., 2015).

It is well known that tree canopy affects the infiltration pattern of precipitation in forest stands, leading to inhomogeneous infiltration of nutrients, acids and pollutants into the forest topsoil (Böttcher and Strebel, 1988; Böttcher et al., 1997). With respect to beech trees, higher leaching rates in the vicinity of tree stems may cause enhanced acidification, which might affect the wetting properties of soil organic components like humic or fulvic acids (Tschapek, 1984). Correspondingly, it can be expected that the amount and composition of SOM in the topsoil varies according to site-specific infiltration patterns. Small scale heterogeneity in WR has been identified for nearsurface soils (Dekker and Ritsema, 1994; Hallett et al., 2004) but almost nothing is known about larger scale variability of the wetting properties of forest soils such as the systematical impact of tree canopy or tree roots.

Some studies addressed mechanisms to couple $\mathrm{pH}$ and CA and showed controversial results. The addition of lime (Roper, 2005) and sodium hydroxide (Karnok et al., 1993) as a tool to increase soil $\mathrm{pH}$ was documented to improve soil wettability. The opposite behaviour was observed for humic acid when the ambient pH was decreased (Terashima et al., 2004). Bayer and Schaumann (2007) investigated the effect of $\mathrm{pH}$ modifications on WR by adding different concentrations of aqueous $\mathrm{NaOH}$ and $\mathrm{HNO}_{3}$ to water repellent and wettable soil with a field $\mathrm{pH}$ between 4.0 and 4.6. They found the maximum WR above the original $\mathrm{pH}$, contradicting the assumption that increasing $\mathrm{pH}$ 
will always increase wettability. A succeeding study (Diehl et al., 2010) developed a new experimental approach by exposing the samples to gaseous $\mathrm{HCl}$ and $\mathrm{NH}_{3}$, thus avoiding the addition of water and a potential dissolution of organic compounds. The authors explained different WR trends with $\mathrm{pH}$ with a soil specific impact of $\mathrm{pH}$ on particle surface charge. The maximum WR occurred usually for soils where the specific surface charge density was at minimum or around zero (point of zero charge). Accordingly, WR decreased as $\mathrm{pH}$ increased while negative surface charge density increased due to dissociation of acidic functional groups (Diehl et al., 2010). In conjunction with deprotonation of the surface more polar sites become available to enable the interaction with water molecules via hydrogen bridges. On the other side, increasing WR with decreasing $\mathrm{pH}$ may arise from protonation of basic functional groups such as amine groups.

Increase in rhizosphere $\mathrm{pH}$ of about one $\mathrm{pH}$ unit was observed for wheat and alfalfa, probably caused by preferred nitrogen uptake as nitrate. The increase of $\mathrm{pH}$ was accompanied by decreasing WR which supports some observations on the inverse relationship between CA and pH (Hassan et al., 2014). A study of Lebron et al. (2012) on tropical forest sites showed that the topsoil of pine plantations had a high degree of WR and persistency and that WR was more homogeneously distributed compared with an adjacent native forest. Results showed further that maximum WR occurred between $\mathrm{pH} 4.0-4.5$ and was not observed for $\mathrm{pH}>5.2$. Observed changes of $\mathrm{pH}$ in the rhizosphere suggested that the release of either $\mathrm{H}^{+}$or $\mathrm{OH}^{-}$and $\mathrm{HCO}_{3}{ }^{-}$acts as charge compensation for the uptake of nutrient anions or cations like $\mathrm{NO}_{3}^{-}$or $\mathrm{NH}_{4}^{+}$, which may led to $\mathrm{pH}$ variations in the rhizosphere (Dakora and Phillips, 2002; Nye, 1981).

With respect to soil hydraulic processes, organic coatings can reduce adhesion forces at the water-solid interface compared to the cohesion forces in bulk water, leading to reduced wettability and capillarity of the partly saturated medium (Lamparter et al., 2014). For water to spread along solid surfaces, adhesive forces at the wetting front must exceed the cohesive forces within the bulk water (Adamson, 1990). Strong cohesion between the water molecules finally forces the liquid in capillary systems to reach a static minimum liquid-air and liquid-solid interfacial area counterbalancing capillary and gravity forces (Adamson, 1990). Soils showing high levels of persistent WR form three-phase systems with reduced solidliquid interfacial area and reduced connectivity of the liquid domains (Goebel et al., 2007; Muehl et al., 2012). Macroscopically, WR reduces the infiltration of water (King, 1981), the available water storage capacity in soils (Deurer and Bachmann, 2007), and causes preferential flow in the unsaturated soil (Ritsema et al., 1993; Wessolek et al., 2009). At the catchment scale, water repellent soils promote overland flow (Imeson et al., 1992) and rapid stormflow (Doerr et al., 2003). Findings of Buczko et al. (2007) suggest that changes in WR can be triggered within short time scales (approx. three days), and moreover, that WR can be affected even by moderate changes in precipitation and slightly elevated temperatures. Particularly under relatively dry conditions, small changes in water content can result in strong changes in WR (Liu et al., 2012).

In order to model the hydraulic properties of water repellent soils, information on the spatial occurrence and pattern of WR is necessary. In one of the few studies dealing with geostatistical analysis of WR patterns, Hallett et al. (2004) suggested that reduced water infiltration may be linked with small scale microbial and/or chemical processes that cause the spatial varia- bility of WR. They concluded that small-scale infiltration measurements are needed to detect water sorptivity patterns. Recent studies confirmed for pine forest soil an extended variability of small-scale WR on the cm-scale, which was evaluated by water drop penetration time or contact angle (CA) measurements (Lamparter et al., 2010; Orfanus et al., 2008). In this context, Ganz et al. (2013) confirmed via in-situ tracer infiltration experiments analyzed by electric resistivity tomography (ERT) and hydraulic modeling (HYDRUS-3D) the relevance of WR for subsoil hydrology. Subsoil WR enhances inhomogeneous infiltrating wetting fronts which increase the tendency of subsoil preferential flow as indicated by the saturation overshoot phenomenon (Ganz et al., 2013). That study pointed out that subsoil WR is lower than in topsoils in terms of CA but showed a higher level of persistence (stability in time). This may promote the propagation of initially developed topsoil preferential flow pathways into the subsoil, thus showing the relevance of subsoil WR for hydraulic processes in deeper soil.

Summarized, soil WR shows several levels of spatial variability, ranging from $\mathrm{mm}$ to $\mathrm{dm}$ and even larger and might be affected by several environmental impact factors. The main objective of the present study was to investigate the impact of trees on the wettability pattern in forest top- and subsoils on an intermediate $(\mathrm{m})$ scale. To unravel the systematic effect of tree abundance we extended the analysis to the deeper subsoil to depths of about $2 \mathrm{~m}$. We chose a forest site with a moderate WR and soil development level to avoid a strong WR background as often observed for acid soils like podzolic soils under coniferous or heath vegetation (Woche et al., 2005).

\section{MATERIAL AND METHODS Study Site}

The sampling site is located $40 \mathrm{~km}$ north-west of Hannover, near Nienburg/Weser, Lower Saxony, Germany (52 34'22.115', North, 9¹8'49.762', East). The beech (Fagus sylvatica L.) forest stand 'Grinderwald', established in 1916, developed on Distric Cambisol (IUSS Working Group WRB, 2014) on pleistocene fluvial and aeolian sandy deposits (Saale glaciation). The site is well drained with a groundwater level of $>10 \mathrm{~m}$ depth. Mean annual precipitation (1981-2010; Source: WorldClim; http://worldclim.org) is $718 \mathrm{~mm}$, mean annual temperature is $8.7^{\circ} \mathrm{C}$. Tensiometer and TDR measurements were evaluated from three soil hydraulic stations located in the vicinity of the three transects (distance $<30 \mathrm{~m}$ ). For 2014, each station showed that the depth of the horizontal watershed (lowest depth with permanent downward directed hydraulic gradients during the year) is localized between 150 and $180 \mathrm{~cm}$.

\section{Transects and experimental design}

The transect soil sampling design was chosen to quantify the effect of beech trees on top- and subsoil WR with three independent replicates (T1, T2, T3). A photograph of a $3 \mathrm{~m} \times 2 \mathrm{~m}$ trench (defined as transect T2) is shown in Fig. 1. All transects were directed towards an individual main tree; the closest distance of the trench to the base of the tree stem was approximately $50 \mathrm{~cm}$ at the soil surface. The distance to the nearest neighboring tree was generally $>10 \mathrm{~m}$. All transects were characterized by relatively homogeneous sandy substrates in the top first meter of the profile. More heterogeneous conditions were found in the subsoil with thin loamy-silty lenses embedded in a sandy matrix which also contain gravel and stones at some locations. Table 1 shows data and the typical soil horizons from a soil pit in the vicinity of the transect locations where soil type 

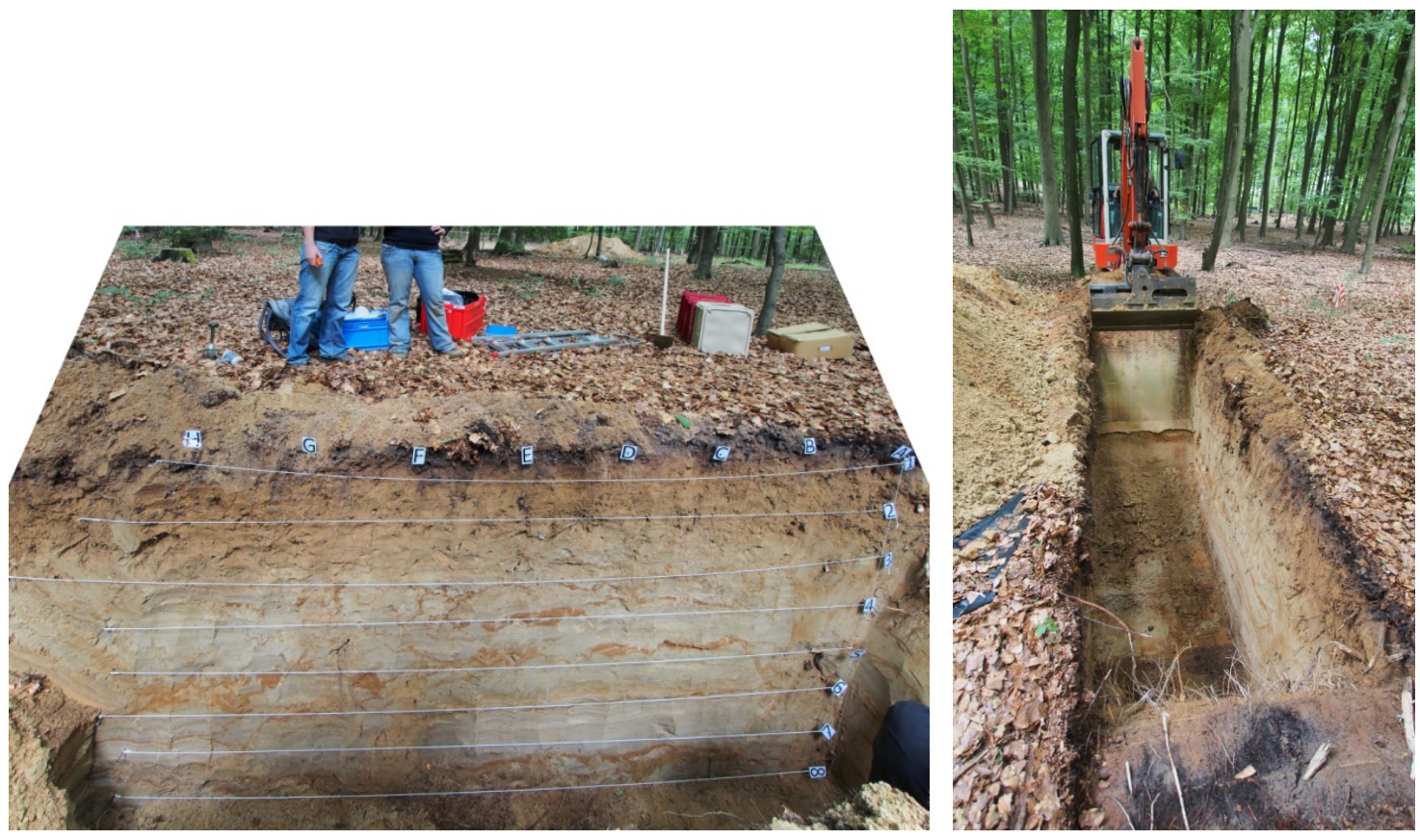

Fig. 1. Image of Transect 2 (left). Lines show the horizontal position of sampling locations $A$ to $H(\Delta x=45 \mathrm{~cm})$; depth increments $\Delta z=10$, $35,60,85,110,135,160,185 \mathrm{~cm}$. The image on the right shows the view directly from the adjacent tree.

Table 1. Characterization of the podzolic Cambisol at site Grinderwald. Soil horizons according to FAO-WRB (IUSS Working Group WRB, 2014). In brackets: soil horizons according to the German Classification Manual, KA5 (Ad-hoc-Arbeitsgruppe Boden, 2005).

\begin{tabular}{l|c|c|c|ccc}
\hline Soil horizon & $\begin{array}{c}\text { Depth } \\
(\mathrm{cm})\end{array}$ & $\mathrm{pH}\left(\mathrm{CaCl}_{2}\right)$ & $\begin{array}{c}\text { SOC } \\
(\%)\end{array}$ & $\begin{array}{r}\text { Sand } \\
(\%)\end{array}$ & $\begin{array}{c}\text { Silt } \\
(\%)\end{array}$ \\
\hline $\mathrm{AE}(\mathrm{Ahe})$ & $0-2$ & 3.3 & 27 & 70 & 26 & 4 \\
$\mathrm{Bsw}(\mathrm{Bsv})$ & $2-12$ & 3.4 & 17 & 65 & 30 & 5 \\
$\mathrm{Bw}(\mathrm{Bv})$ & $12-36$ & 4.4 & 7 & 67 & 29 & 4 \\
$\mathrm{BwC}(\mathrm{Bv} / \mathrm{C})$ & $36-65$ & 4.5 & 3 & 73 & 24 & 3 \\
$\mathrm{C}(\mathrm{C})$ & $65-125$ & 4.4 & 0.4 & 95 & 4 & 1 \\
2C (IIC) & $125-150$ & 4.1 & 0.1 & 81 & 11 & 8 \\
2Cg (IICg) & $150-180$ & 4.2 & 0.8 & 72 & 19 & 9 \\
3C (IIIC) & $>180$ & 4.2 & $<0.1$ & 95 & 4 & 1 \\
\hline
\end{tabular}

and soil horizons were typecast. The organic layer of the forest soil was characterized as 'moder' (L horizon: $0-0.5 \mathrm{~cm}$, F horizon: $0.5-2.7 \mathrm{~cm}$, and $\mathrm{H}$ horizon: $2.7-5 \mathrm{~cm}$ in thickness).

Soil samples were taken on the $10^{\text {th }}$ and $11^{\text {th }}$ of June 2013. Steel cores $(8.5 \mathrm{~cm}$ in diameter, $6 \mathrm{~cm}$ in height with a volume of $248.5 \mathrm{~cm}^{3}$ ) were taken at each grid intersect. Soil material was sampled along all three replicate transects (T1-T3); grid dimension was $200 \mathrm{~cm}$ in vertical and $315 \mathrm{~cm}$ in horizontal direction. Probed distances were $10 \mathrm{~cm}, 35 \mathrm{~cm}, 60 \mathrm{~cm}, 85 \mathrm{~cm}$, $110 \mathrm{~cm}, 135 \mathrm{~cm}, 160 \mathrm{~cm}$, and $185 \mathrm{~cm}$ in vertical direction and 0 cm (A), $45 \mathrm{~cm}$ (B), $90 \mathrm{~cm}$ (C), $135 \mathrm{~cm}$ (D), $180 \mathrm{~cm}$ (E), $225 \mathrm{~cm}$ (F), $270 \mathrm{~cm}(\mathrm{G})$, and $315 \mathrm{~cm}(\mathrm{I})$ in horizontal direction. Accuracy of coordinates was about $1 \mathrm{~cm}$. After sampling, soil was stored in plastic bags until sieving $<2 \mathrm{~mm}$. Samples were airdried and stored at room temperature.

\section{Analytical methods \\ Bulk analyses}

Soil texture was analyzed by an Analysette 22 (Fritsch, IdarOberstein, Germany), and $\mathrm{pH}$ (in $\mathrm{CaCl}_{2}$ ) was measured with a soil to solution ratio of $1: 2.5$. Bulk organic $\mathrm{C}$ and $\mathrm{N}$ contents were determined by dry combustion with a Vario EL-Analyser (Elementar, Hanau, Germany).

\section{Contact angle measurement}

The CA was determined with the sessile drop method (SDM) as described by Goebel et al. (2013). A microscope (OCA 15, DataPhysics, Filderstadt, Germany) equipped with a video camera (approximately 30 frames per second) was used to measure the CA. Ideally, a one-grain layer of homogenized soil material (thickness and roughness depending on average texture of the sample) was fixed on a glass slide in contact with double-sided adhesive tape to avoid movement of the particles during measurement. Droplets $(3 \mu \mathrm{L})$ of distilled water were placed on the horizontally attached sample. After $30 \mathrm{~ms}$ the initial CA of each drop was determined with the Software SCA20 (DataPhysics). The mean value of 6 drops (12 readings in total) was used for further analysis. SDM was chosen due to short measuring times, high reproducibility and repeatability combined with the unlimited measuring range of CA between $0^{\circ}$ and $180^{\circ}$ (Bachmann et al., 2003). It should be noted, however, that soil wettability can only be measured in terms of an apparent (phenomenological) CA for several reasons: The results depend on the size and shape of the particles, on the combined influence of roughness and homogeneity of organic film coatings that cover the soil particles, and on timedependent processes on particle surfaces like rearrangement of molecular structure of the interphase during contact with water 
(Schaumann et al., 2013). Therefore, results for different soils are only comparable when methods are precisely standardized (Bachmann et al., 2003).

\section{Statistical data evaluation}

Classical statistical parameters were calculated according to standard methods (e.g. Snedecor and Cochran, 1980). Regression analyses were made with SigmaPlot 11.0 (Systat Software GmbH, Erkrath, Germany).

\section{RESULTS}

Table 2 summarizes the arithmetic means of basic physical and chemical properties for T1-T3. Data are computed using the entire data set of 64 samples per transect. Mean values suggest a sandy texture with differences in sand content of about $10 \%$. Average soil organic carbon (SOC) contents were between 0.2 and $0.3 \%$, and average $\mathrm{pH}$ values were between 3.8 and 4.1. Average CA were between $5^{\circ}$ and $13^{\circ}$, indicating a low level of subcritical WR. Summarized, the means of the selected key properties suggest quite similar conditions for all three transects with some systematic variations from T1 to T3. Standard deviations for T1-T3 were also similar, suggesting a comparable level of spatial variability for the three transects. Coefficient of variation was largest for the CA with more than $100 \%$ which was consistent for all transects. It indicates the highest level of variation for soil wettability compared with texture, $\mathrm{pH}$, and SOC.

Table 2. Mean and standard deviation ( $\pm 1 \mathrm{SD}$ ) of sand content, organic carbon content (SOC), $\mathrm{pH}$, and contact angle of the three transects $(n=64$ samples per transect).

\begin{tabular}{l|c|c|c|c}
\hline & $\begin{array}{c}\text { Sand } \\
\text { content } \\
(\%)\end{array}$ & $\begin{array}{c}\text { SOC } \\
(\%)\end{array}$ & $\begin{array}{c}\mathrm{pH} \\
\left(\mathrm{CaCl}_{2}\right)\end{array}$ & $\begin{array}{c}\text { Contact } \\
\text { angle } \\
\left({ }^{\circ}\right)\end{array}$ \\
\hline $\begin{array}{l}\text { Transect 1 } \\
\text { (T1) }\end{array}$ & $62.6 \pm 22.1$ & $0.33 \pm 0.45$ & $3.8 \pm 0.3$ & $10.5 \pm 16.6$ \\
$\begin{array}{l}\text { Transect 2 } \\
\text { (T2) }\end{array}$ & $72.7 \pm 18.7$ & $0.26 \pm 0.38$ & $4.0 \pm 0.3$ & $13.2 \pm 15.5$ \\
$\begin{array}{l}\text { Transect 3 } \\
\text { (T3) }\end{array}$ & $74.5 \pm 24.0$ & $0.19 \pm 0.30$ & $4.1 \pm 0.2$ & $5.2 \pm 11.2$ \\
\hline
\end{tabular}

Table 3. Mean and standard deviation ( $\pm 1 \mathrm{SD}$ ) of organic carbon content (SOC), $\mathrm{pH}$, and contact angle of the A horizons of the three transects ( $\mathrm{n}=8$ samples per horizon).

\begin{tabular}{c|c|c|c}
\hline & $\begin{array}{c}\text { SOC } \\
(\%)\end{array}$ & $\mathrm{pH}\left(\mathrm{CaCl}_{2}\right)$ & $\begin{array}{c}\text { Contact angle } \\
\left({ }^{\circ}\right)\end{array}$ \\
\hline Transect 1 (T1) & $1.49 \pm 0.12$ & $3.21 \pm 0.08$ & $47.7 \pm 3.5$ \\
Transect 2 (T2) & $1.12 \pm 0.19$ & $3.43 \pm 0.17$ & $24.4 \pm 25.1$ \\
Transect 3 (T3) & $0.85 \pm 0.24$ & $3.89 \pm 0.32$ & $0.2 \pm 17.7$ \\
\hline
\end{tabular}

Figure 2 displays CA (a), SOC content (b) and $\mathrm{pH}$ (c) for T2 as contour plots (side view of the transect). Side of the transect adjacent to the tree (distance $0.5 \mathrm{~m}$ ) is marked by $\mathrm{x}=0$.

Consistent with T1 and T3, we observed for the mapped CA large wettable domains in the subsoil and also partly in the topsoil. CA greater than $60^{\circ}$ observed in T2 were either located in the A horizon close to the mineral soil surface or in thin layers deeper than $150 \mathrm{~cm}$. In comparison, T3 had a lower SOC content in the A horizon and very low maximum $\mathrm{CA}\left(<10^{\circ}\right)$ in the entire A horizon, while T1 with a higher SOC level in the A than T3 showed CA from $30^{\circ}$ to $60^{\circ}$ along the transect (Table 3).

Regarding A-horizon wettability, transect T2 showed an intermediate characteristic between $\mathrm{T} 1$ and $\mathrm{T} 3$ with the highest level of variation. Only the side away from the tree $(x>150 \mathrm{~cm})$ showed $\mathrm{CA}>10^{\circ}$ for the A horizon (Fig. 2a), which was not reflected by corresponding $\mathrm{SOC}$ or $\mathrm{pH}$ variations along the transect in the A horizon at T2. As indicated in Table 3, CA of T1 were greater (ranging from $33^{\circ}$ to $77^{\circ}$; Fig. 3 ), whereas most $\mathrm{CA}$ of $\mathrm{T} 3$ were around $0^{\circ}$, confirming the intermediate level of $\mathrm{T} 2$ compared with $\mathrm{T} 1$ and $\mathrm{T} 3$.

Also indicated in Fig. 2a, some subsoil samples with a low SOC content, i.e. $<0.3 \%$, showed subcritical WR (CA range: $\left.20-60^{\circ}\right)$ at roughly $1.5 \mathrm{~m}$ depth. Those domains were located for T2 at subsoil positions characterized roughly by $\mathrm{pH}<4$ (Fig. 2c). Similar pH dependencies were not found in the topsoil because for $\mathrm{pH}$ values $<4$ the corresponding CA were in the entire range from 0 to $>60^{\circ}$. It is worth to note that higher WR in small subsoil domains were also observed for T1 and T3 (Fig. 4). The location of these WR spots, however, was not clearly related to tree position or depth as shown exemplary for T2, where the spot occurred at a position most remote from the tree $(\mathrm{x}=200-300 \mathrm{~cm})$. For T3, a similar spot was roughly located at the same position with respect to distance and depth, whereas for $\mathrm{T} 1$ such a domain in the subsoil was smaller, closer to the tree $(2 \mathrm{~m})$ and closer to the surface $(1.0 \mathrm{~m}$ depth).

Figure 3 shows the CA vs. SOC and N content for T1-T3. At SOC contents of approximately around $0.25 \%$ all transects exhibited small CA, i.e. T1 and T2 showed a minimum with $\mathrm{CA} \leq 10^{\circ}$. For lower SOC contents all transects showed again a CA increase, while for SOC $>0.4 \%$ the CA increased clearly for $\mathrm{T} 1$, partly for $\mathrm{T} 2$, but not for $\mathrm{T} 3$, where all CA remained on the low level observed for SOC contents around $0.4 \%$. As mentioned, T3 with the lowest average SOC content in the A horizon and highest average $\mathrm{pH}$ showed no further $\mathrm{CA}$ increase with SOC in the first two sampling depths. The graphs with $\mathrm{N}$ content as independent variable (Fig. 3, right) generally also show an increase in CA with $\mathrm{N}$ content for $\mathrm{T} 1$ and partly for $\mathrm{T} 2$ but not for T3. The major difference to the relationship between $\mathrm{SOC}$ and CA is apparently that for $\mathrm{N}$ the minimum observed for SOC is missing. The occurrence of a minimum for the SOC vs. CA relationship was first described by Ellerbrock et al. (2005) for three forest soils in Germany. That study reported a CA minimum at a slightly higher SOC content of $0.9-1.0 \%$ for the finer textured soils.

Figure 4 shows depth functions of mean and standard deviation for all investigated parameters. SOC content (Fig. 4, row b) decreased monotonically with depth for all transects. In contrast, $\mathrm{N}$ content increased again in the subsoil for $\mathrm{T} 1$ and $\mathrm{T} 2$ at greater depth, expressed by a still decreasing $\mathrm{C} / \mathrm{N}$ ratio (Fig. 4, row d) which indicates a continuous transition of SOM composition with depth. Due to the low SOC content in the subsoil of T3 corresponding values are missing here. The CAdepth relationship (Fig. 4, row a) indicates for $\mathrm{T} 1$ and $\mathrm{T} 2$ decreasing CA for the first two depths to a minimum at about $60 \mathrm{~cm}$. Figure 4 reveals that the CA decrease was not accompanied by systematic textural changes (row f) for all transects but depended for $\mathrm{T} 1$ and $\mathrm{T} 2$ for the first three sampling depths apparently on the $\mathrm{pH}$ (row e), i.e. $\mathrm{pH}$ increase lower than one unit from $0-60 \mathrm{~cm}$ depth changes CA from around $50^{\circ}(\mathrm{T} 1)$ or $25^{\circ}(\mathrm{T} 2)$ to almost zero. It is interesting to note that the $\mathrm{CA}$ increase in the A horizon and the upper $\mathrm{B}$ horizon was not observed for $\mathrm{T} 3$ which is characterized by a mean $\mathrm{pH}$ of about 0.7 units higher in the A horizon. In the deeper subsoil a CA increase was observed at $120 \mathrm{~cm}$ (T1) or 


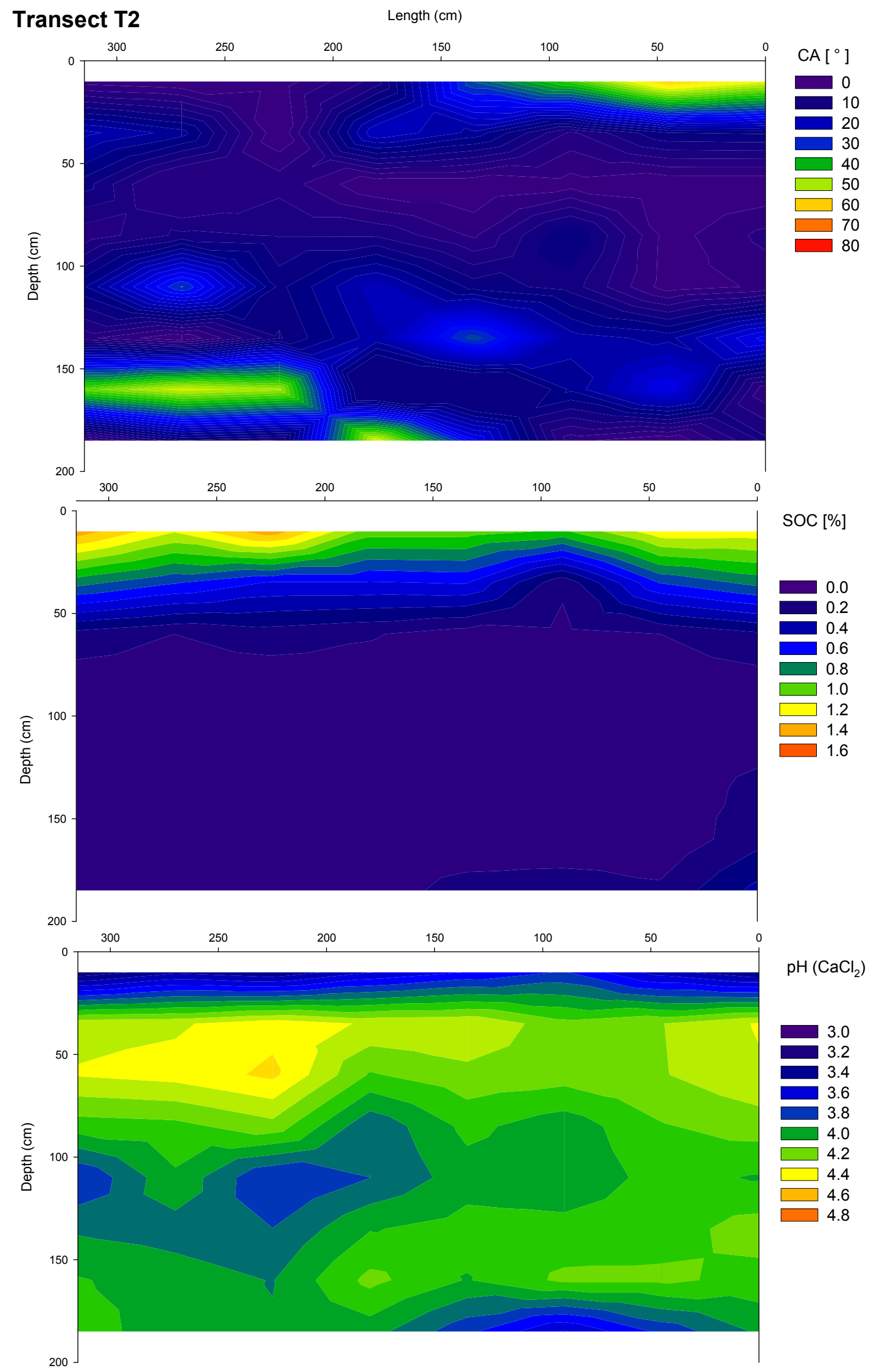

Fig. 2. Contour plots of contact angle (CA), SOC content and $\mathrm{pH}$ for transect $\mathrm{T} 2$. Horizontal value of ' 0 ' indicates the end of the transect directed to the tree. 

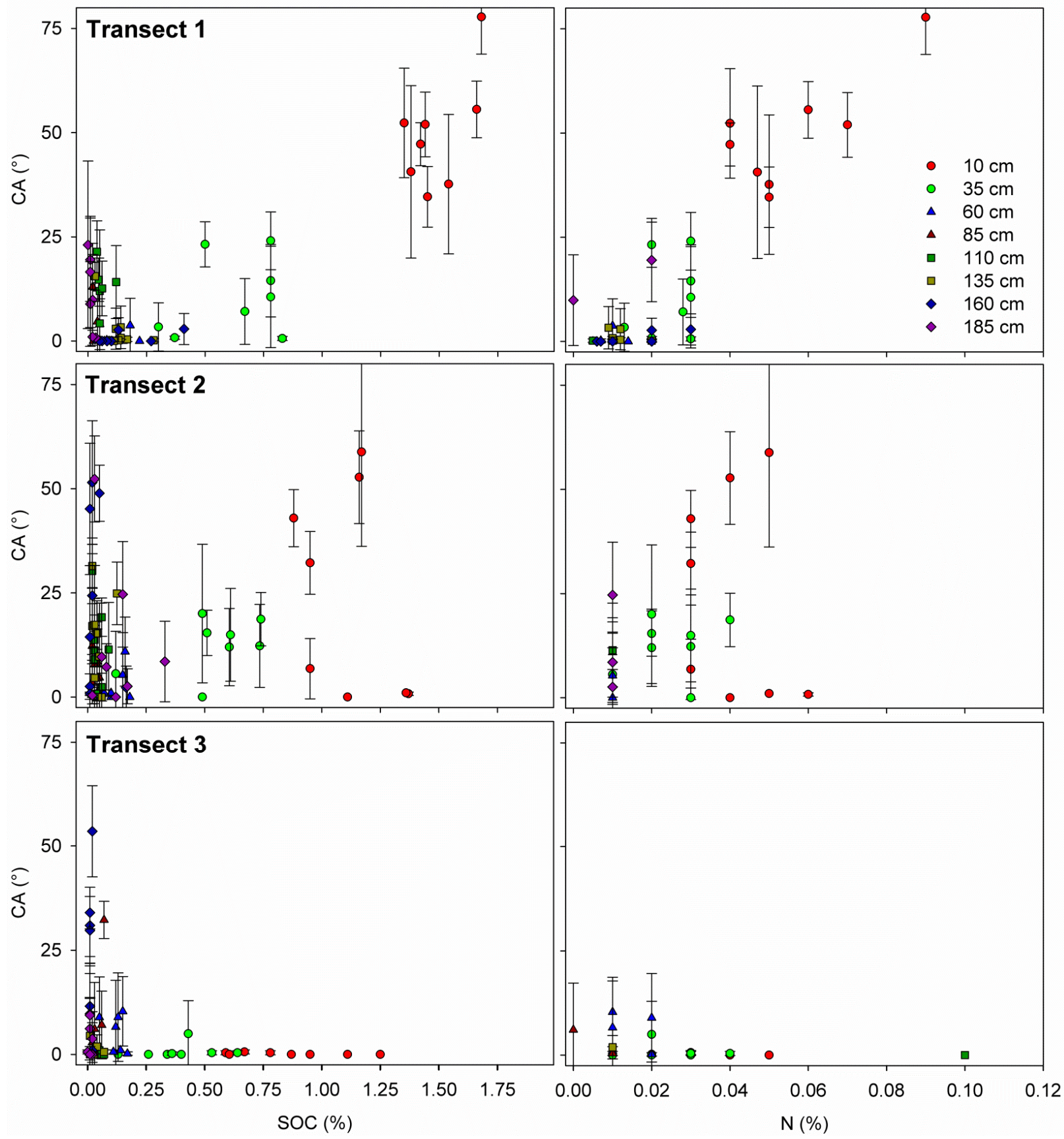

Fig. 3. Contact angle (CA) vs. organic carbon content and nitrogen (SOC) for transects T1-T3.

deeper at $150 \mathrm{~cm}$ depth (T2, T3). On the other hand, the CA increase in the subsoil was more pronounced for T2 and T3 compared with T1 with the greatest CA increase in both transects around $150 \mathrm{~cm}$ depth. Depth functions of the sand content of T2 and T3 show no significant changes in the profile to a depth $>100 \mathrm{~cm}$, indicating, similar to $\mathrm{T} 1$, that texture, i.e. the specific surface area, is not a major variable determining WR variation with depth.

Summarized, Figs. 3 and 4 indicate that the most significant parameters in determining WR are the SOC and N contents. A corresponding general relationship of $\mathrm{CA}$ with $\mathrm{pH}$ could not be found. For example, summarizing the CA vs. pH data from $\mathrm{T} 1-$ $\mathrm{T} 3$ into one plot, the $\mathrm{pH}$ value shows a less specific impact on the CA (Fig. 5).

A general trend to smaller $\mathrm{CA}$ was indicated for $\mathrm{pH}>4$, whereas for smaller $\mathrm{pH}$ values a wide range from $0^{\circ}$ to almost $80^{\circ}$ was evident. Statistically, the multiple linear regression analysis which involved the independent variables SOC, N, and $\mathrm{pH}$ and the dependent variable CA showed ambiguous results. According to the relationship between SOC and CA shown in Fig. 3, we split the data into two sets with SOC $>0.25 \%$ and SOC $<0.25 \%$ (Table 4 ).

The most significant regression was obtained for T1 (SOC > $0.25 \%$ ) with $r^{2}=0.86$ on the $P<0.001$ significance level. Less significant was the regression for transect T2 with $r^{2}$ values $<$ 0.15 for both SOC domains, expressing the CA characteristic of still increasing CA with SOC but also showing the occurrence of samples with $\mathrm{CA}$ of $0^{\circ}$. Less significant regressions were also obtained for $\mathrm{T} 3$ and $\mathrm{T} 1$ for samples with SOC contents $<0.25 \%$, indicating that neither the $\mathrm{pH}$ nor the SOC content is able to explain the spectrum of observed CA in the low SOC domain. With respect to the regression parameters displayed in 


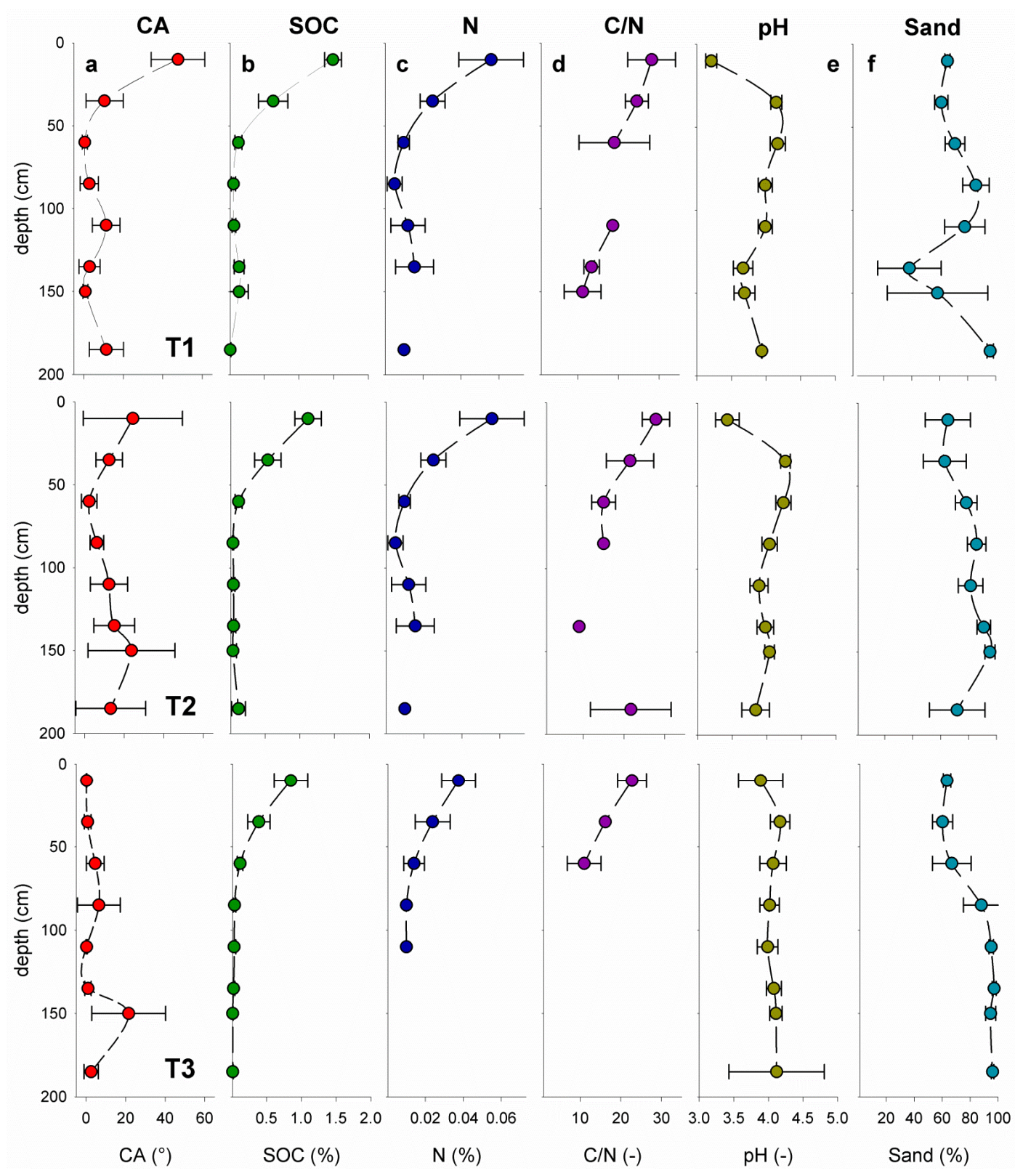

Fig. 4. Contact angle (CA), organic carbon content (SOC), nitrogen content $(\mathrm{N}), \mathrm{C} / \mathrm{N}$ ratio, $\mathrm{pH}$, and sand content as a function of profile depth for transects T1-T3. Missing values indicate samples below detection limit for $\mathrm{N}$ analysis.

Table 4, no systematic trend can be observed, probably due to two reasons: A relatively small variation of key variables for the majority of the subsoil samples and apparently the occurrence of high CA and zero CA samples for the same SOC content shown for T2 at SOC $>0.25$. Summarizing, data for all transects in the low and high SOC domain yielded also low $r^{2}$ values between 0.31 and 0.06 (Table 4). It is finally interesting to note that an adsorbed SOC content of $<0.1 \%$ turned out to be effective in increasing the $\mathrm{CA}$ from $30^{\circ}$ to $>70^{\circ}$, which points out clearly the importance of only small amounts of SOM in affecting subsoil wettability.

\section{DISCUSSION}

Ellerbrock et al. (2005) reported that the degree of soil WR depends not only on the total amount of SOM. Similar to the results of this study they found for three sandy and loamy forest sites a minimum in WR at low SOC contents. To explain the existence of a CA minimum with respect to SOC content they proposed the following mechanisms: In the case of low SOC content in relation to the number of sorption sites of the initially uncoated mineral surface, the hydrophilic groups of the amphiphilic organic molecules are directed towards the mineral surface to form bindings with the mineral interface, e.g. via cation bridges.

After adsorption, hydrophobic moieties like carbohydrate backbone chains are directed towards the pore space making the surfaces more water repellent (stage 1). Continued adsorption leads then from a flat to a more upright position of the outer molecules with an increasing number of hydrophilic sites exposed to the solid-liquid interface (stage 2, maximum wettability after adsorption of SOM), while even higher amounts of adsorbed organic molecules led to a more complex bundle-like structure at the interface (stage 3 ). This complex 
Table 4. Linear multiple regression analysis of the relationship between $\mathrm{CA}$ vs. SOC, $\mathrm{pH}$, and $\mathrm{N}$ content.

\begin{tabular}{|c|c|c|c|}
\hline \multicolumn{2}{|c|}{$C>0.25 \%$} & \multirow[b]{2}{*}{$r^{2}=0.86$} & \multirow[b]{2}{*}{$P \leq 0.001^{*}$} \\
\hline $\mathrm{T} 1:$ & $C A=-3.89+25.1 \cdot C+448.8 \cdot N-3.07 \cdot p H$ & & \\
\hline $\mathrm{T} 2:$ & $C A=32.4-19.9 \cdot C+196.3 \cdot N-4.08 \cdot p H$ & $r^{2}=0.09$ & $P=0.794$ \\
\hline T3: & $C A=0.045+1.49 \cdot C-72.4 \cdot N+0.34 \cdot p H$ & $r^{2}=0.15$ & $P=0.614$ \\
\hline $\mathrm{T} 1:$ & $C A=12.2+38.1 \cdot C-6.20 \cdot p H$ & $r^{2}=0.84$ & $P \leq 0.001^{*}$ \\
\hline $\mathrm{T} 2:$ & $C A=48,5+1.04 \cdot C-8.04 \cdot p H$ & $r^{2}=0.04$ & $P=0.753$ \\
\hline T3: & $C A=-4.94+0.15 \cdot C+1.32 \cdot p H$ & $r^{2}=0.08$ & $P=0.643$ \\
\hline \multicolumn{2}{|c|}{$C<0.25 \%$} & & \\
\hline T1: & $C A=-10.8-55.0 \cdot C+394.2 \cdot N+3.96 \cdot p H$ & $r^{2}=0.46$ & $P=0.022$ \\
\hline $\mathrm{T} 2:$ & $C A=39.4-8.6 \cdot C+0.00 \cdot N-7 \cdot 64 p H$ & $r^{2}=0.11$ & $P=0.755$ \\
\hline T3: & $C A=-69.5+1.65 \cdot C-26.5 \cdot N+18.2 \cdot p H$ & $r^{2}=0.46$ & $P=0.260$ \\
\hline T1: & $C A=3.7-65.1 \cdot C+1.69 \cdot p H$ & $r^{2}=0.26$ & $P=0.003^{*}$ \\
\hline T2: & $C A=64.0-77.5 \cdot C-11.75 \cdot p H$ & $r^{2}=0.10$ & $P=0.087$ \\
\hline T3: & $C A=-12.4-19.6 \cdot C+4.67 \cdot p H$ & $r^{2}=0.01$ & $P=0.779$ \\
\hline$C>0.25 \%$ & $C A=5.72+9.9 \cdot C+0.23 \cdot p H$ & $r^{2}=0.31$ & $P=0.022$ \\
\hline \multicolumn{2}{|c|}{$C<0.25 \%$} & $r^{2}=0.059$ & $P=0.005^{*}$ \\
\hline
\end{tabular}

${ }^{*}$ Significant at the $95 \%$ level.

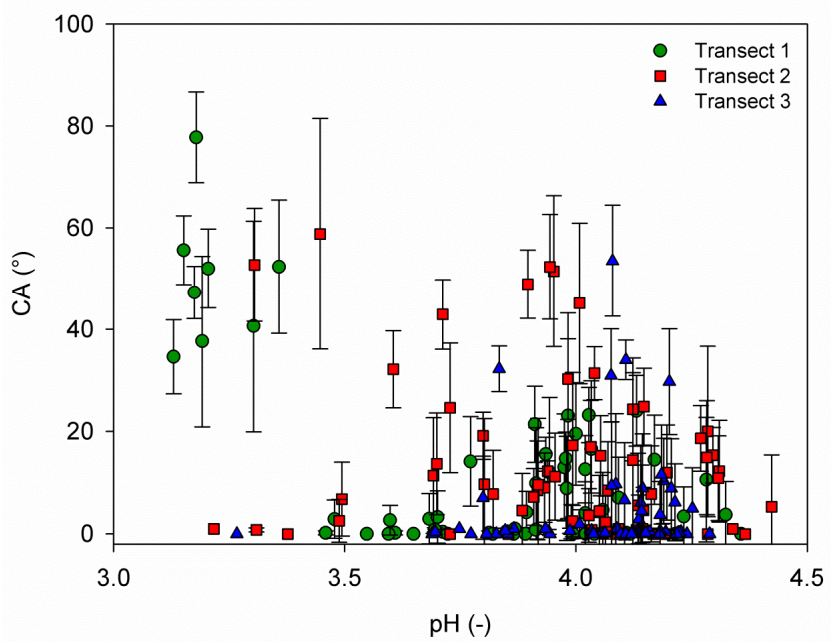

Fig. 5. Contact angle (CA) vs. pH. Summarized data set for data from transects $\mathrm{T} 1-\mathrm{T} 3$.

structure is able to produce varying states of wettability depending on the environmental conditions. A possible impact factor influencing WR in stage 3 is the spatial macromolecular structure, modified i) by polycation bridges, ii) molecular rearrangement, and iii) cross-linking effects (Schaumann et al., 2013), turning either polar or non-polar molecular structures of amphiphilic organic molecules (Tschapek, 1984) towards the surface. Stage 3 might be attributed to the SOC domain $>0.25 \%$. The differences in CA in the 'high SOC' domain between tran- sects $\mathrm{T} 1$ and $\mathrm{T} 3$ might be explained by $\mathrm{pH}$ differences in the $\mathrm{A}$ horizon. Laboratory studies revealed that the type of exchangeable cations adsorbed at exchange sites of extracted humic acids significantly affects their wettability, whereas adsorption of either $\mathrm{H}^{+}$or $\mathrm{Al}^{3+}$ produced a maximum in WR (Tschapek et al., 1984). However, in case of more complex systems such as unfractionated soil, corresponding effects could not be clearly verified. In a recent study by Diehl et al. (2014), where nonfractionated peat and Spodosol material was treated with differently charged cations, i.e. $\mathrm{H}^{+}, \mathrm{Na}^{+}, \mathrm{Ca}^{2+}, \mathrm{Al}^{3+}$, a maximum of WR for $\mathrm{H}^{+}$- and $\mathrm{Al}^{3+}$-treated samples could not be reproduced. On the other hand, in a study by Woche et al. (2005), analyzing several arable and forest soils ranging from $\mathrm{pH} 3.0$ to 6.8 , a significant inverse correlation between $\mathrm{CA}$ and $\mathrm{pH}$ was found which is in agreement with the general tendency found for the topsoils of this study.

According to the model of Ellerbrock et al. (2005) subsoil samples (attributable to stage 1) should be treated differently. Increasing CA with decreasing SOC content suggests that the effectiveness of SOM to render wettable mineral surfaces water repellent does not primarily depend on the amount of SOM. It rather seems that the relative amount of effective water repellent molecular structures in the subsoil SOM were higher compared to the topsoil, where higher amounts of SOM are needed to reach or exceed the level of WR measured for subsoil samples. Ellerbrock et al. (2005) reported the CA minimum for SOC contents around $1.0 \%$ for forest soils with textures ranging from sand to loam. Corresponding FT-IR spectra which reflect the interfacial properties down to $1 \mu \mathrm{m}$ depth (Ferguson and Whitesides, 1992) revealed further that the occurrence of hydrophilic polar functional groups was inversely related to the 
CA, i.e. higher for wettable samples, whereas a reduction in wettability was observed with increasing abundance of hydrophobic (non-polar) molecular structures, leading to a CA increase from $52^{\circ}$ to $88^{\circ}$ (Ellerbrock et al., 2005). This result suggested a direct relationship between the spectroscopic signal of the organic material and wettability. The importance of the outermost molecular arrangement for the wettability of glass surfaces was recently shown by Šolc et al. (2015). Using molecular force field simulations they demonstrated that surface hydrophilicity of ultra-thin siloxane coatings is directly related to the concentration of polar hydroxyl groups and their accessibility for the water molecules. Šolc et al. (2015) further showed that decreasing concentration of hydroxyl groups leads to increasing hydrophobicity and larger CA in the same way as predicted by the FT-IR study by Ellerbrock et al. (2005) for more complex soil particle surfaces. Diehl et al. (2014) showed preliminary results to relate surface elemental composition in the interface of about $1 \mathrm{~nm}$ depth with WR using X-ray photoelectron spectroscopy (XPS). Results show that the element ratio of $\mathrm{O}$ to $\mathrm{C}$ was related to $\mathrm{WR}$, hence the chemical composition of the thin interface governs particle wettability.

Regarding the differences in wettability observed for topand subsoil, different mechanisms of SOM enrichment are reasonable. With respect to the subsoil, the potential of adsorbed water-soluble organic compounds in modifying particle wettability has been reported by Lamparter et al. (2014). Wettability of washed quartz sand was found to decrease significantly after sorption of dissolved organic matter components. It is still unclear, however, if the composition of the adsorbed organic components is depending on the depth in the soil profile. With respect to soil hydrology at the Grinderwald site it is evident that the water repellent subsoil domains in the low SOC domain around $0.25 \%$ are in tendency located below the horizontal watershed (defined as soil depth where the hydraulic gradient is directed downward over the entire year). This hydraulic boundary was identified to be located between $1.5-1.8 \mathrm{~m}$ depth by pressure transducer data measured continuously from 2013 to 2014 at three independent soil hydraulic field stations which were located within a radius $<30 \mathrm{~m}$ from the transects.

Some final remarks should be mentioned here: Not considered in this study is the fundamental effect of solutes on soil WR (Anderson et al., 1995; Hartge, 1958). Increasing liquid surface tension may lead to greater CA, whereas a reduction in liquid surface tension may decrease the CA. Liming of forest soils could increase the liquid surface tension of soil solution which increases potentially the CA. However, at present no further information is available on the properties of the soil solution at the Grinderwald site. Analyzing the simultaneous effect of both mechanisms with respect to soil WR is subject of further investigations.

\section{CONCLUSIONS}

Soil wettability in the field depends on the distribution of SOM and its composition which usually varies considerably in the unsaturated zone. Commonly it is reported that wettability increased with decreasing SOC content, especially in subsoils according to the SOC depth gradient (Dekker and Ritsema, 2003). The testing site used for the present investigation is not expected to show a high level of WR. Correspondingly, CA were in the subcritical range $\left(0^{\circ}<\mathrm{CA}<90^{\circ}\right)$ and become smaller with depth and decreasing SOC content until the minimum at SOC around $0.25 \%$. However, samples from depths $>1 \mathrm{~m}$ revealed increasing $\mathrm{CA}$ with decreasing SOC content. A general feature of all transects is that minimum CA were measured at SOC contents ranging from $0.25 \%$, whereas at smaller or larger SOC contents, the CA increase in case of two transects, characterized by slightly lower $\mathrm{pH}$ as compared to the third transect. In the low SOC domain $<0.25 \%$, WR did not show clear tendencies with respect to single parameters like texture, $\mathrm{pH}$, or $\mathrm{N}$ content, except the general trend of increasing CA with decreasing SOC content for some samples. For the A horizon (high SOC domain) the impact of $\mathrm{pH}$ has additionally to be considered. In our study a $\mathrm{pH}$ of 3.5 seems to be a threshold value in a sense that topsoil samples with $\mathrm{pH}>3.5$ showed generally good wettability. Significant impact of the tree distance on WR could not be observed for the topsoil, whereas for the subsoil WR tends to occur in transect domains farer away from the tree.

We conclude from our study that two reasons might be responsible for the relatively weak correlation between the observed WR and the investigated basic soil parameters. Concerning the sample volume it might be probable that WR variability, especially for the subsoil samples, is smaller than sample volume and spatial differences in WR and SOC are equalized. For forest soils, Lamparter et al. (2010) found pronounced smallscale variability of $\mathrm{CA}$ at the $\mathrm{cm}$ scale, which was considerably smaller than the sample volume of about $0.25 \mathrm{~L}$ content used in the present study. A second reason is related to spatial resolution: bulk soil CA analysis does not necessarily consider the wettability of the interfaces. Adjusted techniques with respect to surface properties are required to link physicochemical properties of the interface like surface charge, surface energy or the chemical composition of the interfase with wettability.

Generally, increasing WR promotes on-site preferential flow pathways which might be important on the catchment scale with respect to runoff and flood events. For our testing site, the level of subsoil WR is low for large parts of the soil, except of some isolated domains in the deeper subsoil. For the future, however, predicted larger frequencies of extended droughts due to climate change suggest a higher probability for the occurrence of WR in deciduous or mixed coniferous forests stands in central Europe.

Acknowledgements. The authors like to thank the Deutsche Forschungsgemeinschaft DFG for financial support within the Research Group 'SUBSOM', BA 1359/13-1 and BA 1359/14-1. We also thank Martin Volkmann for technical assistance.

\section{REFERENCES}

Adamson, A.W., 1990. Physical Chemistry of Surfaces. $5^{\text {th }}$ ed. John Wiley \& Sons, New York.

Ad-hoc-Arbeitsgruppe Boden, 2005. Bodenkundliche Kartieranleitung. [Soil Mapping Manual]. $5^{\text {th }}$ ed. Federal Institute for Geosciences and Natural Resources in cooperation with the Geological Services of the Federal States, Hannover. (In German.)

Anderson, M.A., Hung, A.Y.C., Mills, D., Scott, M.S., 1995. Factors affecting the surface tension of soil solutions and solutions of humic acids. Soil Sci., 160, 111-116.

Bachmann, J., Woche, S.K., Goebel, M.O., Kirkham, M.B., Horton, R., 2003. Extended methodology for determining wetting properties of porous media. Water Resour. Res., 39, doi: 10.1029/2003WR002143.

Bachmann, J., Guggenberger, G., Baumgartl, T., Ellerbrock, R.H., Urbanek, E., Goebel, M.O., Kaiser, K., Horn, R., Fischer, W.R., 2008. Physical carbon sequestration mecha- 
nisms under special consideration of soil wettability. J. Plant Nutr. Soil Sci., 171, 14-26.

Bayer, J., Schaumann, G.E., 2007. Development of soil water repellency in the course of isothermal drying and upon $\mathrm{pH}$ changes in two urban soils. Hydrol. Process., 21, 22662275.

Blackwell, P.S., 2003. Management of water repellency in Australia. In: Ritsema, C.J., Dekker, L.W. (Eds): Soil water repellency - Occurrence, Consequences, and Amelioration. Elsevier, Amsterdam, pp. 291-302.

Böttcher, J., Strebel, O., 1988. Spatial variability of groundwater solute concentrations at the water table under arable land and coniferous forest. Part 1: Methods for quantifying spatial variability (geostatistics, time series analysis, Fourier transform smoothing). J. Plant Nutr. Soil Sci., 151, 185-190.

Böttcher, J., Lauer, S., Strebel, O., Puhlmann, M., 1997. Spatial variability of canopy throughfall and groundwater sulfate concentrations under a pine stand. J. Environ. Qual., 26, 503-510.

Buczko, U., Bens, O., Hüttl, R.F., 2007. Changes in soil water repellency in a pine-beech forest transformation chronosequence: Influence of antecedent rainfall and air temperatures. Ecol. Eng., 31, 154-164.

Dakora, F.D., Phillips, D.A., 2002. Root exudates as mediators of mineral acquisition in low-nutrient environments. Plant Soil, 245, 35-47.

DeBano, L.F., 1981.Water repellent soils: A state of art. USDA Forest Service General Technical Report, PSW-46.

Dekker, L.W., Ritsema, C.J., 1994. How water moves in a water repellent sandy soil: I Potential and actual waterrepellency. Water Resour. Res., 30, 2507-2517.

Dekker, L.W., Ritsema, C.J., 2003. Wetting patterns in water repellent Dutch soils. In: Ritsema, C.J., Dekker, L.W. (Eds): Soil water repellency - Occurrence, Consequences, and Amelioration. Elsevier, Amsterdam, pp. 151-166.

Deurer, M., Bachmann, J., 2007. Modelling water movement in heterogeneous water-repellent soil: 2: Numerical simulation. Vadose Zone J., 6, 446-457, doi:10.2136/vzj2006.0061.

Diehl, D., Bayer, J.V., Woche, S.K., Bryant, R., Doerr, S.H., Schaumann, G.E., 2010. Reaction of soil water repellency to artificially induced changes in soil pH. Geoderma, 158, 375384.

Diehl, D., Schneckenburger, T., Krüger, J., Goebel, M.O., Woche, S.K., Schwarz, J., Shchegolikhina, A., Lang, F., Marschner, B., Thiele-Bruhn, S., Bachmann, J., Schaumann, G.E., 2014. Effect of multivalent cations, temperature and aging on soil organic matter interfacial properties. Environ. Chem., 11, 709-718.

Doerr, S.H., Shakesby, R.A., Walsh, R.P.D., 2000. Soil water repellency: its causes, characteristics and hydrogeomorphological significance. Earth Sci. Rev., 51, 33-65.

Doerr, S.H., Ferreira, A.J.D., Walsh, R.P.D., Shakesby, R.A., Leighton-Boyce, G., Coelho, C.O.A., 2003. Soil water repellency as a potential parameter in rainfall-runoff modelling: experimental evidence at point to catchment scales from Portugal. Hydrol. Process., 17, 363-377.

Ellerbrock, R.H., Gerke, H.H., Bachmann, J., Goebel, M.O., 2005. Composition of organic matter for explaining wettability of three forest soils. Soil Sci. Soc. Am. J., 69, 57-66.

Ferguson, G.S., Whitesides, G.M., 1992. Thermal Reconstruction of the Functionalized Interface of Polyethylene Carboxylic Acid and its Derivates. In: Schrader, M.E., Loeb, G.I. (Eds.): Modern Approaches to Wettability - Theory and Applications. Plenum Press, New York, pp. 143-177.
Ganz, C., Bachmann, J., Noell, U., Lamparter, A., Duijnisveld, W.H.M., 2013. Hydraulic modeling and in situ electrical resistivity tomography (ERT) to analyze the ponded infiltration process into a water repellent sand. Vadose Zone J., doi: 10.2136/vzj2013.04.0074.

Goebel, M.O., Woche, S.K., Bachmann, J., Lamparter, A., Fischer, W.R., 2007. Significance of wettability-induced changes in microscopic water distribution for soil organic matter decomposition. Soil Sci. Soc. Am. J., 71, 1593-1599.

Goebel, M.O., Woche, S.K., Abraham, P.M., Schaumann, G.E., Bachmann, J., 2013. Water repellency enhances the deposition of negatively charged hydrophilic colloids in a watersaturated sand matrix. Colloids Surf. A, 431, 150-160.

Hallett, P.D., Nunan, N., Douglas, J.T., Young, I.M., 2004. Millimeter-scale spatial variability in soil water sorptivity. Soil Sci. Soc. Am. J., 68, 352-358.

Hartge, K.H., 1958. Die Wirkung des Kalkes auf die Strukturstabilität von Ackerböden. [Effect of lime on the soil aggregate stability of arable land]. Dissertation. Department of Horticulture, Technical University of Hannover, Germany. (In German.)

Hassan, M., Woche, S.K., Bachmann, J., 2014. How the root zone modifies soil wettability: Model experiments with alfalfa and wheat. J. Plant Nutr. Soil Sci., 177, 448-458.

Horne, D.J., McIntosh, J.C., 2000. Hydrophobic compounds in sands in New Zealand - extraction, characterisation and proposed mechanisms for repellency expression. J. Hydrol., $231,35-46$.

Imeson, A.C., Verstraten, J.M., van Mulligen, E.J., Sevink, J., 1992. The effects of fire and water repellency on infiltration and runoff under Mediterranean type forest. Catena, 19, $345-361$.

IUSS Working Group WRB, 2014. World Reference Base for Soil Resources 2014. International soil classification system for naming soils and creating legends for soil maps. World Soil Resources Reports No. 106. FAO, Rome.

Karnok, K.A., Rowland, E.J., Tan, K.H., 1993. High pH treatments and the alleviation of soil hydrophobicity on golf greens. Agron. J., 85, 983-986.

King, P.M., 1981. Comparison of methods for measuring severity of water repellence of sandy soils and assessment of some factors that affect its measurement. Austr. J. Soil Res., 19, 275-285.

Lamparter, A., Bachmann, J., Woche, S.K., 2010. Determination of small-scale spatial heterogeneity of water repellency in sandy soils. Soil Sci. Soc. Am. J., 74, 2010-2012.

Lamparter, A., Bachmann, J., Woche, S.K., Goebel, M.O., 2014. Biogeochemical interface formation: Wettability affected by organic matter sorption and microbial activity. Vadose Zone J., 13, doi: 10.2136/vzj2013.10.0175.

Lebron, I., Robinson, D.A., Oatham, M., Wuddivira, M.N., 2012. Soil water repellency and $\mathrm{pH}$ soil change under tropical pine plantations compared with native tropical forest. J. Hydrol., 414, 194-200.

Liu, H., Ren, T. Horton, R., Bachmann, J., 2012. Moisturedependent soil wettability and its influences on soil water retention curve. Soil Sci. Soc. Am. J., 76, 342-349.

Muehl, G.J.H., Ruehlmann, J., Goebel, M.O., Bachmann, J., 2012. Application of confocal laser scanning microscopy (CLSM) to visualize the effect of porous media wettability on unsaturated pore water configuration. J. Soils Sediments, $12,75-85$.

Nye, P.H., 1981. Changes of $\mathrm{pH}$ across the rhizosphere induced by roots. Plant Soil, 61, 7-26. 
Orfanus, T., Bedrna, Z., Lichner, L., Hallett, P.D., Knava, K., Sebin, M., 2008. Spatial variability of water repellency in a pine forest soil. Soil Water Res., 3, 123-129.

Ritsema, C.J., Dekker, L.W., Hendrickx, J.M.H., Hamminga, W., 1993. Preferential flow mechanism in a water repellent sandy soil. Water Resour. Res., 29, 2183-2193.

Roper, M.M., 2005. Managing soils to enhance the potential for bioremediation of water repellency. Austr. J. Soil Res., 43, 803-810.

Schaumann, G.E., Diehl, D., Bertmer, M., Jaeger, A., Conte, P., Alonzo, G., Bachmann, J., 2013. Combined proton NMR wideline and NMR relaxometry to study SOM-water interactions of cation-treated soils. J. Hydrol. Hydromech., 61, $50-63$.

Snedecor, G.W., Cochran, W.G., 1980. Statistical Methods. $7^{\text {th }}$ ed. The Iowa State University Press, Ames Iowa.

Šolc, R., Tunega, D., Gerzabek, M.H., Woche, S.K., Bachmann, J., 2015. Wettability of organically coated tridymite surface - Molecular dynamics study. Pure Appl. Chem., 87, 405-413.

Terashima, M., Fukushima, M., Tanaka, S., 2004. Influence of $\mathrm{pH}$ on the surface activity of humic acid: micelle-like aggregate formation and interfacial adsorption. Colloids Surf. A, 247, 77-83.
Tschapek, M., 1984. Criteria for determining the hydrophilicity-hydrophobicity of soils. Z. Pflanzenern. Bodenk., 147, 137-149.

Wessolek, G., Stoffregen, H., Täumer, K., 2009. Persistency of flow patterns in a water repellent sandy soil - Conclusions of TDR readings and a time-delayed double tracer experiment. J. Hydrol., 375, 524-535.

Woche, S.K., Goebel, M.O., Kirkham, M.B., Horton, R., van der Ploeg, R.R., Bachmann, J., 2005. Contact angle of soils as affected by depth, texture, and land management. Eur. J. Soil Sci., 56, 239-251.

WorldClim - Global Climate Data, Model e: http://worldclim.org.

Zisman, W.A., 1964. Relation of equilibrium contact angle to liquid and solid construction. In: Gould, R.F. (Ed.): Contact Angle, Wettability and Adhesion. Advan. Chem. Series, 43, Amer. Chem. Soc., Washington, D.C., pp. 1-51.

Received 14 July 2015 Accepted 4 November 2015 